\title{
LÍNEAS DE POTENCIA COMO LÍNEAS DE TRANSMISIÓN
}

\section{POWER LINES AS TRANSMISSION LINES}

\author{
MSc. (c) Eduardo Castillo C., MSc. Harold A. Romo R., MSc. Juan F. Flórez M. \\ Universidad del Cauca. Department of Electronics, Instrumentation, and Control. \\ Calle 5, No. 4 - 70, Popayán, Cauca, Colombia, Tel.: (+572) 8209800. \\ E-mail: \{eduardocastillo, hromo, jflorez\}@unicauca.edu.co.
}

\begin{abstract}
Resumen: En este artículo se analiza el comportamiento de una línea de potencia de núcleo entorchado frente a una de núcleo sólido, cuando son estas usadas como líneas de transmisión en sistemas PLC. Para su análisis, se considera el modelo de parámetros distribuidos de resistencia, inductancia, capacitancia y conductancia, de una línea de potencia como línea de transmisión basada en la teoría de dos puertos. La diferencia básica en el comportamiento de las líneas de transmisión propuestas es debido al factor de corrección de la resistencia (XR), introducido por la línea núcleo entorchado; este factor presenta respuesta en frecuencia inversa a la resistencia, logrando ecualizar la atenuación de la línea de transmisión. Concluyendo en el diseño de sistemas de comunicación sobre la red eléctrica que el uso de líneas de núcleo entorchado como líneas de transmisión tiene mejor desempeño frente a líneas núcleo sólido.
\end{abstract}

Palabras clave: Líneas de potencia, Líneas de trasmisión, núcleo sólido, núcleo entorchado, factor de corrección, frecuencia.

\begin{abstract}
This paper describes the behavior of a stranded core power line compared to the behavior of a solid core power line, when they are used as transmission lines in power line communication systems. For this analysis, the model of resistance, inductance, capacitance, and conductance distributed parameters of a power line as a transmission line based on the two-port theory is considered. The basic difference in the behavior of proposed transmission lines is due to the resistance correction factor (XR), introduced by the stranded core line; this factor has an inverse frequency response of the resistance parameter, achieving attenuation equalization of the transmission line. Concluding that in power line communication systems design, the use of stranded core lines as transmission lines has better performance versus solid core lines.
\end{abstract}

Keywords: Power lines, transmission lines, stranded core, solid core, correction factor, frequency.

\section{INTRODUCTION}

Currently, Power Line Communication (PLC) systems are of great interest due to their advantages and applications (Wei 2011), (Pang et al. 2012), (Berger, Schwager, and Escudero-Garzás 2013). These use power lines as transmission lines, being less costly compared to coaxial cables, and fiber optic systems, among others (Mlynek, Misurec, and Koutny 2011). Because power lines are not manufactured for data transport (Acosta et al. 2006), (Zaw, Kyaw, and Ye 2013), computer simulations are effective tools in the optimal design of PLC systems (Zaw et al. 2013), (Singh and Sharma 2013), (Li and Zhang 2014). 
Among the works aimed at characterizing and simulating power lines as transmission lines, there are: (Tsuzuki et al. 2001), which models and simulates a Vinyl insulation, Vinyl sheath, Flat (VVF) line, employing two-port theory in a frequency range up to $30 \mathrm{MHz}$; (Misurec and Orgon 2011), which models and simulates two lines; one $3 \times 1.5 \mathrm{CYKY}$ and another $3 \times 2.5 \mathrm{AYKY}$, employing two-port theory in a frequency range up to $8 \mathrm{MHz}$, besides modeling and simulating an electric motor controlled by PLC systems; (Mlynek et al. 2012), which models and simulates $3 \times 1.5$, $3 \times 2.5$, and $3 \times 4$ CYKY lines, employing two-port theory in a frequency range up to $1 \mathrm{GHz}$ and analyzes the response of one of these lines in a test topology.

These previous reports, although modeling, simulating, and analyzing the frequency response of two types of power lines individually, do not present a comparative analysis of their performance - an important aspect in the design and deployment of PLC systems. Our work considers the solid core line type $1 * 8+8$ AWG Aluminum AL Insulating XLPE and the stranded core line type $1 * 6+6$ AWG Aluminum Al-8000 Insulating XLPE, analyzing their frequency responses within a range from $3 \mathrm{KHz}$ to $30 \mathrm{MHz}$, according to respective resistance $(\mathrm{R})$, inductance (L), capacitance (C), and conductance (G) parameters.

\section{MODEL OF A POWER LINE AS TRANSMISSION LINE}

A power line, seen as transmission line, is characterized by the following four distributed parameters: resistance $(\mathrm{R})[\Omega / \mathrm{m}]$, inductance $(\mathrm{L})$ $[\mathrm{H} / \mathrm{m}]$, capacitance $(\mathrm{C})[\mathrm{F} / \mathrm{m}]$, and conductance $(\mathrm{G})$ $[\mathrm{S} / \mathrm{m}]($ Cheng 1983), modeled in infinitesimal lengths $(\Delta x)$ of the transmission line (Figure 1).

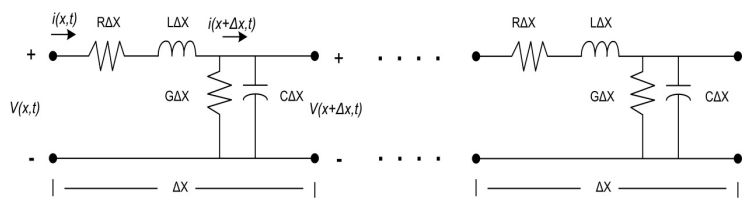

Fig. 1. Model of distributed parameters every $\Delta x$ of the transmission line.

Voltage and instantaneous current in the $x$ position of a $\Delta x$ line segment is denoted by $V(x, t)$ and $I(x, t)$, equations 1 and 2 , respectively (Cheng 1983):

$$
\begin{aligned}
& -\frac{\partial V(x, t)}{\partial x}=R \cdot i(x, t)+L \cdot \frac{\partial i(x, t)}{\partial t}, \\
& -\frac{\partial i(x, t)}{\partial x}=G \cdot V(x, t)+C \cdot \frac{\partial V(x, t)}{\partial t},
\end{aligned}
$$

The ordinary differential equations of the transmission lines, equations 3 and 4, are obtained from the phasor representation of equations 1 and 2:

$$
\begin{aligned}
& -\frac{d V(x)}{d x}=(R+j \cdot w \cdot L) \cdot \mathrm{I}(x), \\
& -\frac{d \mathrm{I}(x)}{d x}=(G+j \cdot w \cdot C) \cdot V(x)
\end{aligned}
$$

By replacing equations 3 and 4 in the second derivate, with respect to $\mathrm{x}$, from the same equations, we obtain the ordinary second order one-dimensional differential equations, equations 5 and 6 (Kraus and Carver 1996):

$$
\begin{gathered}
\frac{d^{2} V(x)}{d x^{2}}=\gamma^{2} \cdot V(x), \\
\frac{d^{2} \mathrm{I}(x)}{d x^{2}}=\gamma^{2} \cdot \mathrm{I}(x),
\end{gathered}
$$

Where $\gamma$ is the propagation constant $\left[\mathrm{m}^{-1}\right]$ (Kraus and Carver 1996), given by:

$$
\gamma=\sqrt{(R+j 2 \pi f L) \cdot(G+j 2 \pi f C)},
$$

Where $f[\mathrm{~Hz}]$ is the frequency.

The solutions of equations 5 and 6 are expressed in equations 8 and 9 , respectively, where the super indexes \pm denote current and voltage traveling in direction $\pm \mathrm{x}$ (Cheng 1983):

$$
\begin{aligned}
& V(x)=V_{0}^{+} \cdot e^{-\gamma x}+V_{0}^{-} \cdot e^{\gamma x}, \\
& \mathrm{I}(x)=\mathrm{I}_{0}^{+} \cdot e^{-\gamma x}+\mathrm{I}_{0}^{-} \cdot e^{\gamma x}
\end{aligned}
$$

Considering in equations 8 and 9 a semi-infinite transmission line, a source from the left side (with no reflected waves), and the signal traveling in direction $+x$; by relating voltage, $\mathrm{V}(x)$, and current, $\mathrm{I}(\mathrm{x})$, we obtain the characteristic impedance for the transmission line $Z_{0}(\Omega)$ (Kraus and Carver 1996) (Lampe and Vinck 2011), equation 10:

$$
Z_{0}=\sqrt{\frac{(R+j 2 \pi f L)}{(G+j 2 \pi f C)}}
$$


The propagation constant and the characteristic line impedance are expressed in terms of distributed parameters and in function of $f$, but not of line length.

\section{1 $\mathrm{R}, \mathrm{L}, \mathrm{C}$, and $\mathrm{G}$ parameters for a power line}

For a power line (Figure 2.a and 2.b), the R, L, C, and $\mathrm{G}$ distributed parameters are expressed in terms of their physical characteristics and are given by equations $11,12,13$, and 14 , respectively (Mlynek et al. 2011):

$$
\begin{array}{lll}
R & =\frac{\sqrt{\mu_{c} \cdot f}}{a \cdot \sqrt{\cdot \sigma_{c} \cdot \pi}} \cdot \frac{D / 2 \cdot a}{\sqrt{\left(\frac{D}{2 \cdot a}\right)^{2}-1},} \quad[\Omega / \mathrm{m}] \\
L=\frac{\mu_{e}}{\pi} \cosh ^{-1}(D / 2 \cdot a)+\frac{R}{2 \cdot \pi \cdot f}, & {[\mathrm{H} / \mathrm{m}]} \\
C=\frac{\pi \cdot \varepsilon}{\cosh ^{-1}(D / 2 \cdot a)}, & {[\mathrm{F} / \mathrm{m}]} \\
G=2 \cdot \pi \cdot \tan \delta \cdot C \cdot f, & {[\mathrm{~S} / \mathrm{m}]}
\end{array}
$$

where: $\mathrm{a}$ is the conductor radius, $\mathrm{D}$ is the separation distance between the center of the lines, $\mathrm{s}_{\mathrm{c}}$ is the electric conductivity, and $\mu \mathrm{c}$ is the magnetic permeability; e is the electric permittivity of the dielectric coating, and $\delta$ is the film effect parameter, and tand is the dissipation factor.

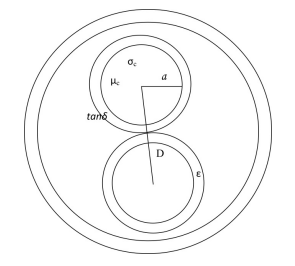

a)

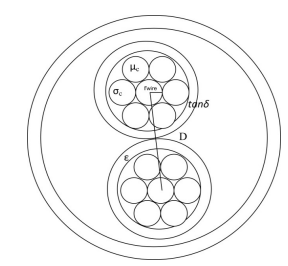

b)

Fig. 2. Power line cross section. a) Solid core b) Stranded core.

The film effect is present in a line when a highfrequency signal flows through it, generating greater flow of the signal close to the surface. Its magnitude represents the signal's penetration depth from the conductor surface and is determined through equation 15 (Meng et al. 2004):

$$
\delta=\frac{1}{\sqrt{\pi \cdot f \cdot \sigma_{c} \cdot \mu_{c}}} .
$$

[m]

Due to this phenomenon, the cross-section area of the conductor through which the signal can circulate is reduced to a ring that tightens as frequency increases, with the signal finding greater resistance in its passage.

It is observed in equations 11 to 14 that the $\mathrm{R}, \mathrm{L}$, and $\mathrm{G}$ parameters are frequency functions; not so for $\mathrm{C}$. This paper presents the respective frequency responses and these are analyzed for both types of lines.

\subsection{Resistance parameter for stranded core power line}

For a stranded core power line, the geometry of the film surface through which the signal flows is modified, given the presence of gaps between the wires that make up the strand (Figure 2.b). Because of the aforementioned, to determine the resistance parameter $\left(\mathrm{R}_{\mathrm{C}}\right)$ of a stranded core line, the resistance of the solid core is affected with the correction factor $\left(\mathrm{X}_{\mathrm{R}}\right)$, thus:

$R_{C}=X_{R} \cdot R$,

With $\mathrm{X}_{\mathrm{R}}$ given by equation 17 :

$$
X_{R}=\frac{\left(\cos ^{-1}\left(\frac{r_{\text {wire }}-\delta}{r_{\text {wire }}}\right) \cdot r_{\text {wire }}^{2}-\left(r_{\text {wire }}-\delta\right) \cdot \sqrt{r_{\text {wire }}^{2}-\left(r_{\text {wire }}-\delta\right)}\right)}{2 \cdot r_{\text {wire }} \cdot \delta},
$$

Where $r_{\text {wire }}$ is the radius of a wire that makes up the strand (Meng et al. 2004).

\section{TYPES OF LINES}

The two types of lines considered; solid core $(1 * 8$ +8 AWG Aluminum - AL - Insulating XLPE) and stranded core $(1 * 6+6$ AWG Aluminum Al-8000 Insulating XLPE), are used in the electric distribution network supplied by the Compañia

\begin{tabular}{|c|c|}
\hline \multicolumn{2}{|c|}{$\begin{array}{c}\text { Stranded core line - Al-8000 } \\
\text { Reference: } 1 * 6+6 \text { AWG Aluminum Al-8000 - } \\
\text { Insulating XLPE }\end{array}$} \\
\hline Line diameter - Phase (m) & $4.29 \mathrm{e}-3$ \\
\hline $\begin{array}{l}\text { Relative magnetic } \\
\text { permeability (approx.) }\end{array}$ & 1 \\
\hline Electric conductivity $(\mathrm{S} / \mathrm{m})$ & $3.53 \mathrm{e} 7$ \\
\hline $\begin{array}{l}\text { Dielectric relative electric } \\
\text { permittivity }\end{array}$ & 2.3 \\
\hline
\end{tabular}
Energética de Occidente S.A.S. E.S.P. in the Department of Cauca - Colombia. Table 1 summarizes the relevant physical characteristics of these lines (Mugala 2005) (Cables de Energia y de Telecomunicaciones S.A. 2014).

\section{Table 1: Stranded core and solid core lines}




\begin{tabular}{l|c}
\hline \multicolumn{2}{c}{ Solid core line - AL } \\
\multicolumn{1}{c}{ Reference: $\mathbf{1} * \mathbf{8}+\mathbf{8}$ AWG Aluminum AL - } \\
Insulating XLPE \\
\hline $\begin{array}{l}\text { Line diameter - Phase (m) } \\
\text { Relative magnetic }\end{array}$ \\
$\begin{array}{l}\text { permeability (approx.) } \\
\text { Electric conductivity (S/m) } \\
\begin{array}{l}\text { Dielectric relative electric } \\
\text { permittivity }\end{array}\end{array}$ \\
\hline
\end{tabular}

\section{SIMULATION AND ANALYSIS OF RESULTS}

The MATLAB $R 2012 b$ software was used for simulation.

\subsection{Frequency response of the correction factor $\left(\mathbf{X}_{\mathbf{R}}\right)$}

Frequency response curves for the XR, R, and RC of the stranded core line (Figure 3).

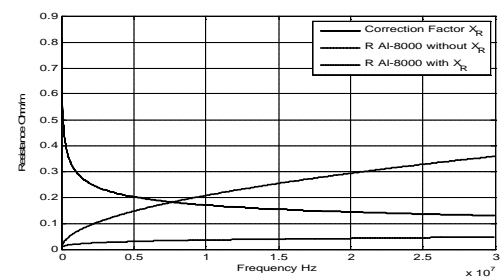

Fig. 3. Frequency response of the correction factor of a stranded core line.

Figure 3 presents the XR inverse behavior with respect to $\mathrm{R}$, achieving attenuation equalization on the stranded core line, managing to minimize the attenuation of the line for frequency ranges from 3 $\mathrm{KHz}$ to $30 \mathrm{MHz}$.

\subsection{Frequency response of $R, L, G$, and $C$ parameters}

Frequency response curves of the R, L, C, and G parameters for the two power lines considered in Table 1 (Figure 4).

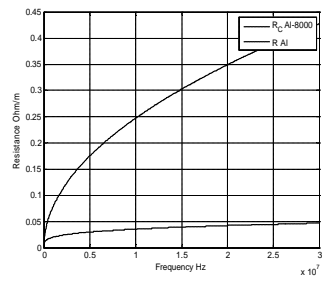

a)

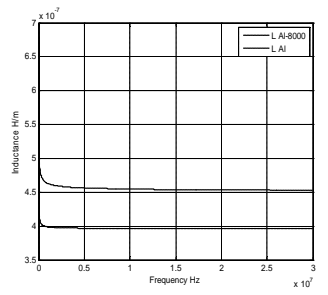

b)
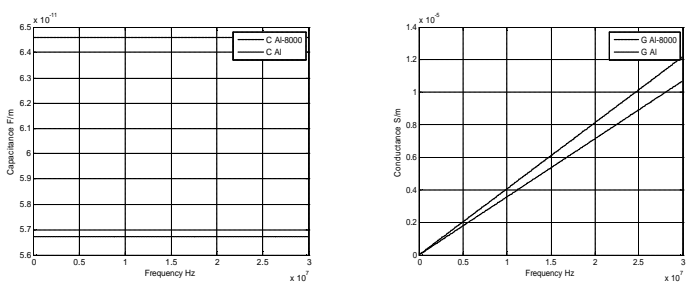

c)

Fig 4. Frequency response of $\mathrm{Al}$ - solid core and Al-8000 lines. a) Resistance ( $R$ and $\left.R_{C}\right)$. b) Inductance ( $L$. . c) Capacitance $(C)$. d) Conductance $(G)$.

Figure 4.a presents better attenuation performance for the stranded core line, maintaining resistance below $0.05[\Omega / \mathrm{m}]$ compared to $0.4[\Omega / \mathrm{m}]$ for the solid core line up to $30 \mathrm{MHz}$; an important aspect in the implementation of PLC systems. Figure 4.b shows that the inductance of the stranded core line is slightly lower than the inductance of the solid core line, with an approximate difference of $1 \times 10^{-7}$ $[\mathrm{H} / \mathrm{m}]$, indicating improved performance of the stranded core line with respect to the solid core line. Figure 4.c presents constant behavior of capacitance against frequency variations, with a small difference between both lines; $\mathrm{C} \cong 6.46 \times 10^{-11}$ and $5.67 \times 10^{-11}[\mathrm{~F} / \mathrm{m}]$ for the stranded core and solid core lines, respectively. The constant behavior of capacitance is because the relative permittivity of the dielectric - XLPE - is independent of frequency for the range of interest (Mugala 2005) (Mugala, Eriksson, and Pettersson 2006) (Zhang et al. 2013). Finally, Figure 4.d shows that conductance for the stranded core line is slightly higher than for the solid core line as frequency increases; however, at $30 \mathrm{MHz}$ the difference does not exceed $0.5 \times 10^{-5}$ $[\mathrm{S} / \mathrm{m}]$.

\section{CONCLUSIONS}

Resistance, inductance, capacitance, and conductance parameters were modeled and simulated for a solid core power line $(1 * 8+8 A W G$ Aluminum-AL-Insulating XLPE) and a stranded core line $(1 * 6+6$ Aluminum Al-8000 - Insulating $X L P E)$ as transmission lines, considering the twoport theory. Additionally, the resistance correction factor was modeled and simulated for a stranded core line. Frequency responses were considered in the range from $3 \mathrm{KHz}$ to $30 \mathrm{MHz}$.

The following are important conclusions:

- Stranded core lines, given their modified core geometry, introduce the effect of attenuation equalization due to the $X_{R}$, whose frequency 
response is inverse to the conductor resistance, being favorable for transmission PLC systems at big distances, given that the signal will be subjected to lower attenuation per meter of line length.

- The XR maintains the line resistance almost constant and below $0.05[\Omega / \mathrm{m}]$ in all frequency ranges simulated.

- The L, G, and C parameters for both types of power lines, in spite of the geometric differences of their respective cores, do not present notable differences that can impact upon the performance of one over the other.

Given the aforementioned, the advantage of stranded core lines is reflected in the resistance parameter, which decisively influences on the distance that can be achieved in a PLC system.

\section{FUNDING}

This research work was funded by Compañia Energética de Occidente S.A.S. E.S.P. in cooperation with Universidad del Cauca within the RD\&I project - ID 3881.

\section{REFERENCES}

Acosta, Antonio Gan, Ing Emerson, R. Puche Pinedo, and Ing José M. Luna A. 2006. "Data Transmission Using the AC Power Transmission Line." Revista Colombiana de Tecnologías de Avanzada 1(7):54-59.

Berger, Lars Torsten, Andreas Schwager, and J. Joaquín Escudero-Garzás. 2013. "Power Line Communications for Smart Grid Applications." Journal of Electrical and Computer Engineering 2013:1-16.

Cables de Energía y de Telecomunicaciones S.A. 2014. "www.centelsa.com". 07 de enero.

Cheng, David K. 1983. Field and Wave Electromagnetics. Addison-Wesley Publishing Company.

Kraus, John D., and Keith R. Carver. 1996. Electromagnetics. 2nd ed. Mcgraw-Hill.

Lampe, Lutz, and A. J. Ha. Vinck. 2011. "On Cooperative Coding for Narrow Band PLC Networks." AEU - International Journal of Electronics and Communications 65:681-87.

Li, Weilin, and Xiaobin Zhang. 2014. "Simulation of the Smart Grid Communications?: Challenges, Techniques, and Future Trends Q." Computer and Electrical Engineering 40:270-88.
Meng, H. et al. 2004. "Modeling of Transfer Characteristics for the Broadband Power Line Communication Channel." IEEE Transactions on Power Delivery 19(3):1057-64.

Misurec, Jiri, and Milos Orgon. 2011. "Modeling of Power Line Transfer of Data for Computer Simulation." International Journal of Communication Networks and Information Security (IJCNIS) 104 3:104-11.

Mlynek, Petr, Jiri Misurec, and Martin Koutny. 2011. "Modeling and Evaluation of Power Line for Smart Grid Communication." Electrical Review 87:228-32.

Mlynek, Petr, Jiri Misurec, Martin Koutny, and Pavel Silhavy. 2012. "Two-Port Network Transfer Function for Power Line Topology Modeling." Radioengineering Journal 21:35663.

Mugala, G., R. Eriksson, and P. Pettersson. 2006. "Comparing Two Measurement Techniques for High Frequency Characterization of Power Cable Semiconducting and Insulating Materials." Dielectrics and Electrical Insulation, IEEE Trans. on 13(4):712-16.

Mugala, Gavita. 2005. "High Frequency Characteristics of Medium Voltage XLPE Power Cables.” KTH Electrical Engineering.

Pang, Qingle, Xinyun Liu, Bo Sun, and Qunli Ling. 2012. "Approximate Entropy Based Fault Localization and Fault Type Recognition for Non-Solidly Earthed Network." Measurement Science Review 12:309-13.

Singh, Brajesh, and Kanchan Sharma. 2013. "Transfer Function and Impulse Response Simulation of Power Line Channel." International Journal of Science and Research (IJSR) 2:322-28.

Tsuzuki, Shinji, Shinji Yamamoto, Takashi Takamatsu, and Yoshio Yamada. 2001. "Measurement of Japanese Indoor Power-Line Channel.” Pp. 6-11 in Proc. 5th Int. Symp.

Wei, Chunjuan. 2011. "Implementation of Automatic Meter Reading System Using PLC and GPRS Components of AMR System System Architecture." Journal of Information \& Computataional Science 16:4343-50.

Zaw, Naing Lin, Hitke Aung Kyaw, and Kyaw Zaw Ye. 2013. "Power Line Cable Transfer Function for the Broadband Power Line Communication Channel." Universal Journal of Control and Automation 1:103-10.

Zhang, Wei et al. 2013. "Time Domain Simulation of PD Propagation in XLPE Cables Considering Frequency Dependent Parameters." International Journal of Smart Grid and Clean Energy 2:25-31. 